\section{ANAESTHETIC PRACTICE 1990}

Presented by the UNIVERSITY OF TORONTO DEPARTMENT OF ANAESTHESIA

Friday and Saturday, November 16, 17, 1990

The Delta Chelsea Inn, 33 Gerard St. W.,

Toronto M5G 1Z4

COURSE CONTENT:

Medico-legal, Regulatory and Quality Assurance

Aspects of Practice

Intra-operative Complications

and Hazards / Common Pediatric Problems

PRACTICAL SESSIONS INCLUDE:

Management of Failed Intubation / Central Venous

Access

Regional Blocks / Dysrythmia Management

GUEST SPEAKER:

Critical Care in the Nineties the Role of the Anaesthetist

Dr. J. Hewson, President of the Canadian Critical Care Society

REGISTRATION FEE:

$\$ 275.00$ before October $15 ; \$ 28.5 .00$ after

FOR FURTHER INFORMATION:

Department of Anaesthesia, University of Toronto Room 132 Fitzgerald Building

150 College Street, Toronto, Ontario, M5S 1A1

Telephone (416) 323-6008

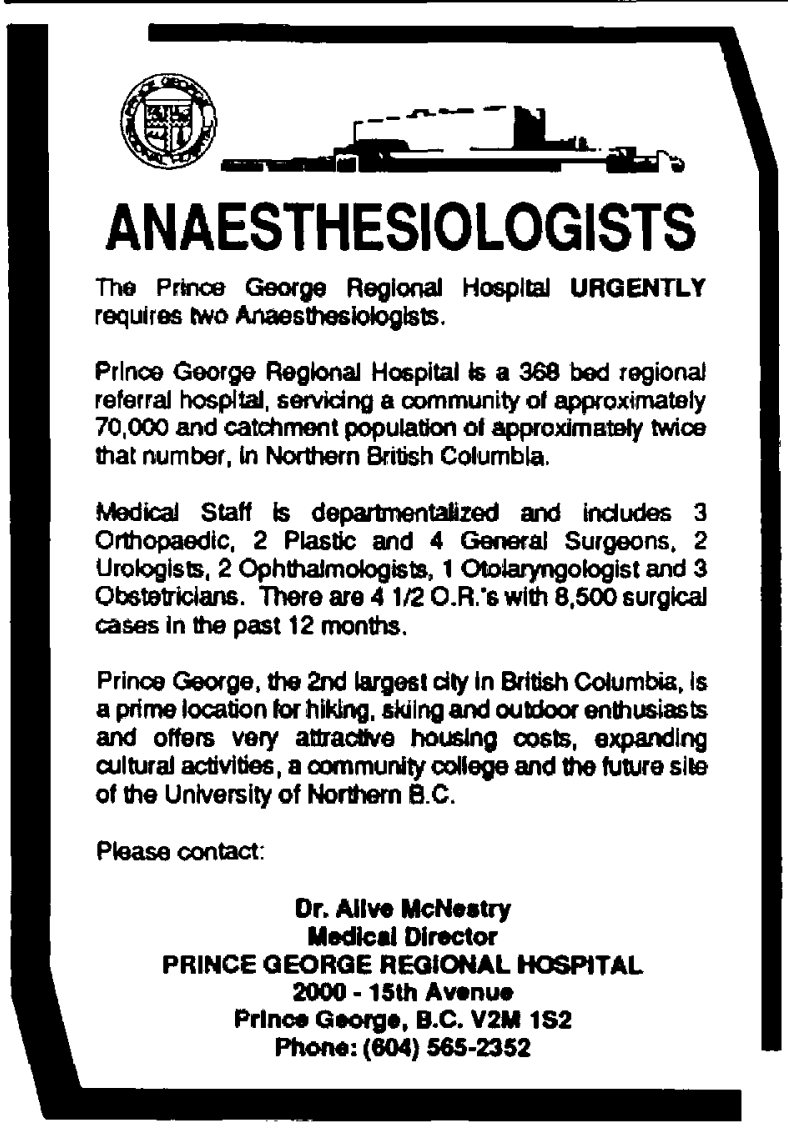

\section{CompHeallh \\ THE THYSICIAN GROUE}

\section{Attention Canadian}

Anesthesiologists eligible to work in U.S. within next six months: Large, profitable anesthesiology group in westen New York state seeks several section directors as well as staff anesthesiologists. This growing MD/CRNA group services modern 500-bed hospital affiliated with major university. Major center for head, neck, breast, and neuro surgery; no trauma or neo-natal. Competitive salary, malpractice insurance and relocation assistance, plus partnership option. All inquiries handled in strictest confidence. Send CV to Samantha Lloyd, CompHealth Anesthesia Search, 5901 Peachtree Dunwoody Rd, \#C-65, Atlanta, GA 30328. Or, for more information, contact Ms. Lloyd at 1-800-354-4050, toll-free.

\section{CHIEF OF ANAESTHESIA}

Central Hospital is an acceredited, 176-hed community hospital. located in the core of demntom Toronto. The Hospital is currently expanding its community services to kecp pace with the evolving needs of its exciung. culturally diverse. downtor'n conmunity. To meet these needs, Ceniral Hospilal is expanding its program of day surgery as an addition to the in-patien services which utilize five $O R$. theatres. To further the development of this program, we are presenly searching fur : new full-time Chief of Anatesthesia and an additional full-time anacsthesiologist.

As Chicf of Anaesthesia, you will head a department of 4 10.5 anaesthesiologusts and exert leadership in maintaining anaesthesia QA and slaff educational programs. Also, while in association with the Chuef of Stuff and Chief of Surgery. you will help ensure the effective utilization of in-patjent and dary surgical facilities.

Send Curriculum Vitue to the Medical Director

CENTRAL

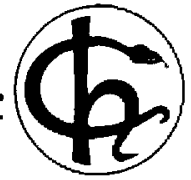
HOSPITAL

333 Sherbourne Street. Toronto. Ontario M5A 2S5 The Best Care in Any Language 